\title{
BMJ Open Assessing the association between tourism and the alcohol urban environment in Barcelona: a cross- sectional study
}

\author{
Susanna Puigcorbé, ${ }^{1,2,3}$ Joan R Villalbí, ${ }^{1,2,3,4}$ Xisca Sureda, ${ }^{5,6,7,8}$ \\ Marina Bosque-Prous (D) , 9,10 Ester Teixidó-Compañó, ${ }^{11}$ Manuel Franco, 5,6,12 \\ Montserrat Bartroli, ${ }^{1,2,3}$ Albert Espelt ${ }^{4,10,11}$
}

To cite: Puigcorbé S, Villalbí JR, Sureda $\mathrm{X}$, et al. Assessing the association between tourism and the alcohol urban environment in Barcelona: a cross-sectional study. BMJ Open 2020;10:e037569. doi:10.1136/ bmjopen-2020-037569

- Prepublication history for this paper is available online. To view these files, please visit the journal online (http://dx.doi org/10.1136/bmjopen-2020037569).

Received 07 February 2020 Revised 12 August 2020 Accepted 23 August 2020
Check for updates

(C) Author(s) (or their employer(s)) 2020. Re-use permitted under CC BY-NC. No commercial re-use. See rights and permissions. Published by BMJ.

For numbered affiliations see end of article.

Correspondence to Dr Marina Bosque-Prous; mbosquep@uoc.edu

\section{ABSTRACT}

Objectives Alcohol availability and promotion are not distributed equally in the urban context. Evidence shows that the socioeconomic level seems to influence the amount of alcohol-related elements in an area. Some studies suggest that tourism could also affect the distribution of these elements. We explore with a valid instrument in a large city whether there is an association between high tourism pressure and a greater presence of alcohol-related elements in the urban environment. Design Observational ecological study.

Setting The study was conducted in Barcelona during 2017-2018.

Participants We assessed urban exposure to alcohol by performing social systematic observation using the OHCITIES Instrument in a stratified random sample of 170 census tracts within the city's 73 neighbourhoods. Primary and secondary outcome measures For each census tract we calculated the density of alcohol premises and of promotion in public places per 1000 residents. We estimated tourism pressure using the number of tourist beds per 1000 residents in each neighbourhood and calculated quartiles. To assess the relationship between rate ratios of elements of alcohol urban environment and tourism pressure, we calculated Spearman correlations and fitted Poisson regression models with robust error variance.

Results The median densities obtained were of 8.18 alcohol premises and of 7.59 alcohol advertising and promotion elements visible from the public space per 1000 population. Census tracts with the highest tourism pressure had 2.5 (95\% Cl: $1.85-3.38)$ times more outlets and $2.3(95 \% \mathrm{Cl}: 1.64-3.23)$ times more promotion elements per 1000 residents than those in the lowest tourism pressure quartile.

Conclusions We observed a strong association between tourism pressure and alcohol exposure in the city of Barcelona.

\section{INTRODUCTION}

Alcohol use is a risk factor for more than 200 diseases and injuries. ${ }^{1}$ Globally, 2.8 million deaths were attributed to alcohol use in 2016. ${ }^{2}$ Many factors influence alcohol use,
Strengths and limitations of this study

- This is the first major study to examine the association between tourism pressure and urban environment elements related to alcohol, availability and advertising or promotion.

- We characterised the alcohol urban environment of a compact city in Southern Europe in a representative sample of census tracts using a validated measuring tool.

- The OHCITIES measuring tool captures important characteristics of the alcohol environment as they are experienced by persons in the street, which are difficult to capture using other methods.

- The study is cross-sectional in nature, and thus no causality may be derived from associations.

among them its availability and affordability. ${ }^{3}$ Alcohol promotion also seems to be linked to alcohol consumption. ${ }^{45}$ The urban environment contains a wide variety of elements related to alcohol availability and to its promotion, such as sales premises and alcohol advertising. Exposure to alcohol-related elements including both points of sale and consumption and alcohol promotion may contribute to normalise its use. ${ }^{6}$ Empirical research has shown it is actually related to higher levels of alcohol use. ${ }^{78}$ In some countries, regulation of alcohol availability and promotion effectively limits its presence, but in the absence of such interventions market forces drive its presence, which finally results from the balance of supply and demand. Some studies have shown a relationship between the density of elements related to alcohol availability and promotion in the urban environment and the socioeconomic level of the area. ${ }^{9-13}$ Other studies suggest that tourism pressure could also have an effect on the distribution of alcohol-related elements ${ }^{14-16}$ 
but, to our knowledge, no study has explored this association in depth.

Barcelona has evolved to become a major tourist destination in the last 25 years. ${ }^{17}$ From not being a tourist destination it has evolved to become the 12th most touristic city worldwide in 2017 , and tourism has grown from 2 million visitors per year in the early 1990 s to 9 million in 2018 (while having 1.6 million residents). ${ }^{18}$ Tourism generates economic benefits ${ }^{19}$ but it may also have undesirable effects, such as increases in the cost of housing and gentrification, or the substitution of traditional community shops for tourist-oriented establishments. ${ }^{172}$ Among the main tourist interests is the local gastronomy including local beverages (such as wine, beer or liquors), and in areas with more tourists business evolves to offer more lodging, eating and drinking options. ${ }^{21-23}$ Nightclubs, bars, restaurants and liquor stores targeting tourists have as their main goal expanding their drinking expenditures, but we may assume that as a side effect they also increase the availability of alcohol for residents, and thus expand their drinking opportunities. ${ }^{14}{ }^{24}$ In Barcelona, where the availability and acceptability of alcohol are widespread, we hypothesise that high tourism pressure may have had an impact increasing the presence of urban elements related to alcohol availability and promotion. As tourism has grown rather abruptly and with an uneven distribution across the city, it is an ideal setting to investigate its effect. ${ }^{19}$ Beyond the statistical analysis, further efforts may focus on clarifying whether urban elements related to alcohol actually exert an influence on alcohol use, and if a derived harm exists.

The objective of this study was to examine the potential relationship between tourism pressure in the city of Barcelona and the presence of two markers of the alcohol availability and promotion in the urban environment: the density of alcohol premises, and the density of alcohol promotion and advertising visible from public space, measured using a validated instrument.

\section{METHODS}

\section{Design}

We conducted an observational ecological study in Barcelona between July 2017 and February 2018. Barcelona is a dense and compact city, with a population of 1.6 million in an area of $100 \mathrm{~km}^{2}$, mostly living in apartments. The municipality is divided into 1068 census tracts within 73 neighbourhoods grouped in 10 districts. Census tracts are the smallest administrative divisions, defining homogeneous territorial zones containing an average of 1000 voters.

\section{Sample}

A representative sample of 170 census tracts was selected (figure 1), covering all neighbourhoods, with an average of two census tracts per neighbourhood. In each census tract, we collected data on various elements related to alcohol availability: on-premises (bars and restaurants)

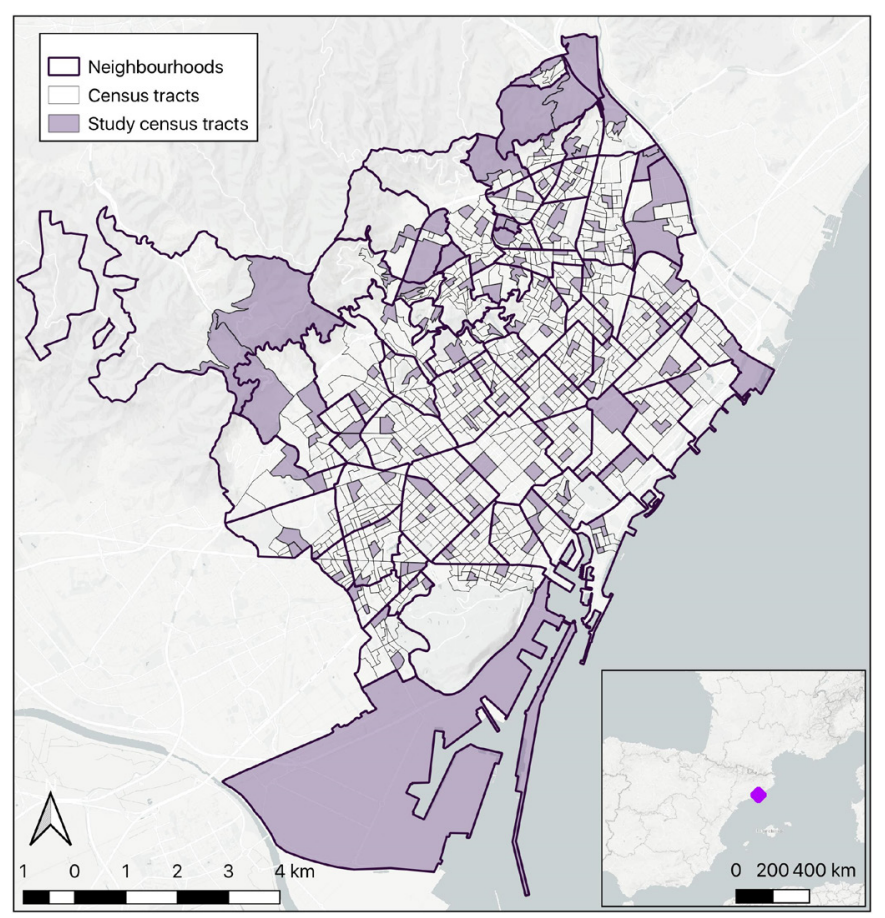

Figure 1 Census tracts and neighbourhoods in Barcelona, with the study census tracts indicated.

and off-premises (retail stores), and advertising and promotion elements in the public space. To obtain representative data for the city, we conducted stratified random sampling of census tracts in each neighbourhood (except for the two neighbourhoods composed of a single census tract, which were both included). In general, we sampled two census tracts for each neighbourhood, but if these covered less than $5 \%$ of the surface, we randomly selected more until $5 \%$ was reached (figure 1 ).

\section{Measures}

Field data collection was carried out using the validated OHCITIES Instrument. ${ }^{25}$ OHCITIES is a questionnaire that uses systematic social observation to characterise different variables related to alcohol availability and promotion in the urban environment. This instrument had been previously developed and validated showing high inter-rater and test-retest reliability values (higher than 0.80 ) for most of its variables. ${ }^{25}$ The OHCITIES Instrument works with a mobile application and we collected the data using a smartphone. It also allowed us to geolocate all the recorded information and to take pictures. Four trained observers completed the observations in the 170 selected tracts, randomly distributed among observers and observation days. As a previous study observed only minor differences between mornings and evenings, ${ }^{15}$ data were collected in working days, 16:0020:00. Although the reliability of OHCITIES has been validated previously, in order to detect whether there were significant differences in data collection between observers and seasons, we performed repeated observations in 37 census tracts (13 in different seasons, 7 with different observers, and 17 with both different observers 
and seasons) and found no significant differences (data not shown).

The main dependent variables for this study were the densities of the urban elements that may foster alcohol consumption: availability of alcohol; and alcohol advertising and promotion visible from the public space. Availability of alcohol included on-premises (bars, restaurants, pubs) and off-premises (supermarkets, grocery stores, specialised alcohol outlets), regardless of whether they were open or closed at the time of the observation. As elements promoting alcohol, we included both the number of premises that had any alcohol advertising or promotion visible from the street (posters, awnings, signs, items with logos in the premises' terrace), and the number of advertising or promotion items located in outdoor public places beyond the outlets (billboards, posters on bus stop shelters, vinyls on urban buses). We obtained the densities of each element by calculating the number of elements recorded in a census tract per 1000 residents in that census tract.

Independent variables were derived from the city statistical reports, which provide most data at the neighbourhood level. Thus, for these variables we ascribed to each census tract its neighbourhood value. The main independent variable was tourism pressure ${ }^{26}$ which we estimated using a previously proposed indicator. ${ }^{26}{ }^{27}$ We created this indicator by computing the number of tourist beds (including hotels, hostels, touristic apartments, bed and breakfast rooms, and other touristic lodgings) in each neighbourhood per population in that neighbourhood in 2016. The density of tourist beds ranged among neighbourhoods from 0 to $674 / 1000$ residents, and its median was $29 / 1000$ residents. The other independent variable was the socioeconomic level, a potential confounding variable as it has been linked to the urban elements related to alcohol. ${ }^{9}$ To estimate neighbourhoods' socioeconomic level, we used the Available Family Income Index (AFII) in 2016, an indicator of per capita wealth, where the mean value for the city is 100 and neighbourhoods rank from 34.3 to $242.4{ }^{28}$ This index combines five weighted socioeconomic variables: education level (proportion of people with a university degree), employment (number of employed people as a proportion of the working-age population), number of vehicles per capita, the engine size of new vehicles purchased by residents and the market price of residences.

\section{Statistical analyses}

We described the number of elements related to alcohol availability and promotion found in the urban environment and its median densities, by level of tourism pressure. Due to the different number of census tracts selected in each neighbourhood, we used sampling weights to obtain more representative values for the whole city. To explore the associations between different alcohol-related variables and tourism pressure, we categorised the density of tourist beds in three groups (1st quartile, quartiles 2-3 and 4th quartile) in order to overcome the wide range of values. We mapped the distribution quartiles of the densities of each variable in the city neighbourhoods. We obtained Spearman correlation coefficients to analyse the relationship between the census tract densities of the alcohol-related variables and tourism pressure. We considered as census tracts enduring high tourism pressure those located in neighbourhoods with the highest quartile of tourist beds relative to the resident population. We fitted Poisson regression models with robust error variance obtaining crude rate ratios for each category with their respective 95\% CIs. We used the lowest level of tourism pressure as the reference category. Finally, to control for confounding by socioeconomic level, we fitted another Poisson regression model with robust error variance adjusting for the neighbourhood AFII. All statistical analyses were carried out using the Stata V.14 software package while the spatial analyses were done with QGIS 3.

\section{RESULTS}

Descriptive analyses of the alcohol urban environment are shown in table 1 . Within the 170 census tracts studied, we identified a total of 5210 urban elements related to alcohol availability and promotion. Of these, 2391 were alcohol outlets: $70 \%$ were on-premise alcohol outlets, $29 \%$ were off-premise alcohol outlets and $1 \%$ were other outlets that sold alcohol as a minor part of the business (such as souvenir shops offering customised sangria bottles). There were 2263 alcohol promotion elements: $80 \%$ were visible alcohol advertising or promotion elements related to alcohol premises; $7 \%$ were alcohol advertising or promotion elements related to commercial settings different from alcohol premises and the remaining $13 \%$ were alcohol advertising or promotion beyond outlets, mostly on streets. In relative terms, the median densities found were 8.18 alcohol-selling premises per 1000 inhabitants and 7.59 alcohol advertising and promotion elements per 1000 inhabitants. The highest densities of both on-premises and off-premises sales and advertising or promotion elements were found in central census tracts, with a strong correlation with the neighbourhood distribution of tourist beds in the city $(\mathrm{p}=0.54$ and $\mathrm{p}=0.49$, respectively). The distribution of the densities of each element in the city neighbourhoods is shown in figure 2, as well as the distribution of tourism pressure and socioeconomic level.

As shown in table 2, we found that tourism pressure was significantly associated with the density of premises that sell alcohol, and with the density of advertising and promotion elements. Neighbourhood socioeconomic level was not associated with alcohol urban environment when adjusting for tourism pressure. Neighbourhoods in the highest quartile of tourism pressure had a rate of alcohol-selling premises and of advertising and promotion elements that were 2.50 (95\% CI: 1.85-3.38) and 2.30 (95\% CI: 1.64-3.23) times greater than those in the bottom quartile, respectively. 
Table 1 Number, median and quartiles of alcohol sales premises and advertising in a sample of the city census tracts, by tourism pressure, Barcelona, 2017-2018

\begin{tabular}{|c|c|c|c|c|c|}
\hline & $\mathbf{n}$ & $\%$ & Q1 $^{*}$ & Median* & Q3 $^{*}$ \\
\hline \multicolumn{6}{|l|}{ Alcohol premises in general } \\
\hline Low tourism pressure & 278 & 11.6 & 4.82 & 6.97 & 9.74 \\
\hline Medium tourism pressure & 974 & 40.7 & 4.68 & 7.19 & 10.25 \\
\hline High tourism pressure & 1139 & 47.7 & 8.52 & 14.55 & 17.83 \\
\hline Total $†$ & 2391 & 100 & 5.36 & 8.18 & 13.88 \\
\hline \multicolumn{6}{|l|}{ On-premises } \\
\hline Low tourism pressure & 185 & 11 & 2.79 & 4.24 & 7.68 \\
\hline Medium tourism pressure & 659 & 39.2 & 2.71 & 4.14 & 6.51 \\
\hline High tourism pressure & 838 & 49.8 & 4.87 & 9.11 & 12.97 \\
\hline Total & 1682 & 100 & 3.19 & 5.15 & 8.64 \\
\hline \multicolumn{6}{|l|}{ Off-premises } \\
\hline Low tourism pressure & 91 & 13.3 & 1.3 & 2.4 & 3.39 \\
\hline Medium tourism pressure & 308 & 44.8 & 1.42 & 2.49 & 3.7 \\
\hline High tourism pressure & 288 & 41.9 & 2.32 & 3.49 & 5.11 \\
\hline Total & 687 & 100 & 1.6 & 2.73 & 3.91 \\
\hline \multicolumn{6}{|l|}{ Advertising and promotion } \\
\hline Low tourism pressure & 283 & 12.5 & 4.1 & 5.64 & 8.58 \\
\hline Medium tourism pressure & 906 & 40 & 4.26 & 6.39 & 9.66 \\
\hline High tourism pressure & 1074 & 47.5 & 8.58 & 11.61 & 16.29 \\
\hline Total $\dagger$ & 2263 & 100 & 5 & 7.59 & 12.37 \\
\hline \multicolumn{6}{|c|}{ Advertising and promotion in public places unrelated to premises } \\
\hline Low tourism pressure & 55 & 18.1 & 0 & 0 & 1.03 \\
\hline Medium tourism pressure & 142 & 46.9 & 0 & 0.82 & 1.57 \\
\hline High tourism pressure & 106 & 35 & 0 & 0.81 & 1.79 \\
\hline Total & 303 & 100 & 0 & 0.78 & 1.57 \\
\hline \multicolumn{6}{|c|}{ Premises with alcohol advertising and promotion elements } \\
\hline Low tourism pressure & 219 & 12 & 4.82 & 4.82 & 8.04 \\
\hline Medium tourism pressure & 709 & 39 & 3.28 & 5.12 & 7 \\
\hline High tourism pressure & 893 & 49 & 6.23 & 10.88 & 13.7 \\
\hline Total & 1821 & 100 & 1.7 & 5.85 & 10.08 \\
\hline
\end{tabular}

Tourism pressure is categorised using quartiles: low: Q1; medium: Q2-Q3; high: Q4.

*Estimation for all Barcelona, densities per 1000 inhabitants (weighted).

†There were further 22 alcohol premises classified as 'other outlets that sold alcohol as a minor part of the business' and 139 alcohol promotion elements classified as 'alcohol advertising or promotion elements related to commercial settings different from alcohol premises' not shown in this table due to small numbers.

\section{DISCUSSION}

The main finding of this study is that the density of alcohol, alcohol-selling premises, and advertising or promotion-related elements in the urban environment varies markedly between the census tracts of Barcelona, and that this variation appears to be now mostly related to tourism pressure. Independently of the socioeconomic level of the neighbourhood, tourism pressure is positively and significantly associated with the density of alcohol outlets, and with advertising and promotion elements. Further, most advertising and promotion elements visible from the public space are essentially placed in alcohol outlets.

This is, to our knowledge, the first major study to examine the association between tourism pressure and the elements related to alcohol availability, advertising or promotion in the urban environment. We characterised the alcohol urban environment of Barcelona in a representative sample of census tracts using a validated measuring tool, the OHCITIES Instrument. ${ }^{25}$ OHCITIES captures important characteristics of the alcohol environment as they are experienced by persons while 

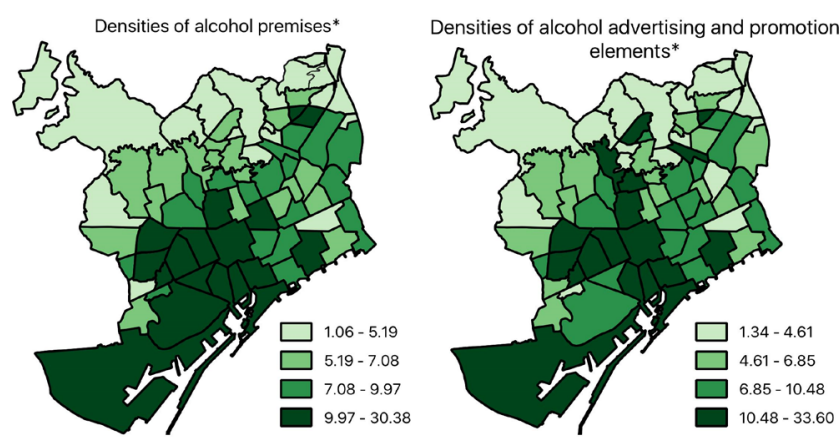

Touristic beds*

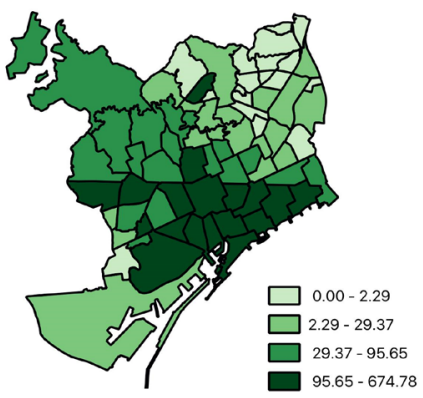

Available family income index
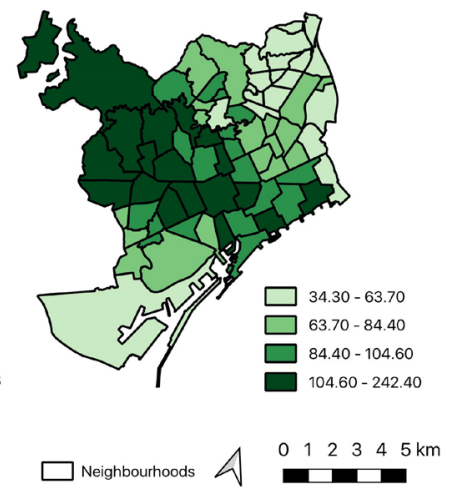

Figure 2 Neighbourhood means of the studied census tracts density of alcohol premises, alcohol promotion elements, Available Family Income Index and touristic beds per 1000 residents, by quartile. Barcelona, 2017-2018. *Densities per 1000 residents in 2016.

in the street, which are difficult to capture using other methods. ${ }^{25}$ It is remarkable that the densities derived in 2015 for the pilot study covering only 20 census tracks but with observations in the morning, afternoon and night periods were fairly close to these estimates. ${ }^{15}$ Although we chose to perform the fieldwork on weekdays between 16:00 and 20:00 to ensure that most on-premises and offpremises sales outlets would be open during data collection, some pubs and nightclubs were closed at the time of the observation. Even though we included all the premises regardless of whether they were open or closed, if some premises had no visible external signs while closed we may had some underestimation results, and this is a limitation of the study. However, as alcohol premises were concentrated in central and touristic areas, the inclusion of these unidentified outlets would have produced even stronger associations. Another potential limitation is the extrapolation of neighbourhood-level data for the independent contextual variables in the studied census tracts. However, as neighbourhoods are relatively homogeneous areas, this should not produce biased results. As the study is cross-sectional in nature, there is no directionality in it, and of course no causality may be derived from the associations found. The question of whether tourism attracts outlets or outlets attract tourism cannot be answered with this observational study.

We found that greater tourism pressure is now associated with a greater density of alcohol outlets and promotion elements in the urban environment. Higher density of alcohol outlets and promotion elements may be conducive to more drinking by the exposed persons, both tourists and permanent residents. ${ }^{29}$ Only a handful of studies explore tourism as a factor related to the alcohol availability or promotion elements. An Australian study found a positive association between tourism pressure and the presence of on-premise and off-premise outlets. ${ }^{13}$ Caribbean islands with high levels of tourism had more outlets and higher levels of alcohol production, import and distribution than islands with lower levels of tourism. ${ }^{14}$ In Cyprus some decades ago, bars were only present in tourist areas, but have expanded to other areas as tourism has grown. ${ }^{16}$ These results are in line with our findings: urban areas in Barcelona that have the greatest tourism pressure also have greater availability of alcohol, and more advertising and promotion elements. However, in Spain and other wine-growing countries of Southern Europe drinking is culturally accepted and drinks are in general widely available and relatively inexpensive ${ }^{3}$ : this context must be kept in mind. In fact, we also found that Barcelona has a high density of elements related to alcohol in its urban environment. While on-premises and off-premises medians obtained in the city were 5.15 and 2.73 per 1000 inhabitants, respectively, the densest areas in Victoria (Australia) have 1.45 on-premises and 0.45 offpremises per 1000 residents. ${ }^{13}$ Also in New Zealand, the reported highest density is 2.01 premises per 1000 residents. ${ }^{30}$ Comparing ratios relative to population ignores the fact that Barcelona is a very compact city, so if we had compared ratios relative to the surface the differences with these studies would be even greater.

Establishments in Spain do not require a specific licence to sell alcohol (either in on-premises or off-premises), allowing alcohol to be more ubiquitously available. There is evidence that tourism pressure in Barcelona has favoured gentrification and the partial substitution of traditional community trade for tourism-oriented establishments. ${ }^{170}$ This leads us to think that a greater supply of alcohol in the tourist areas could be an effect derived, at least partially, from the pressure of tourism. A higher alcohol availability linked to tourism pressure could be a recent process as the city has evolved to become a major tourist destination in a relatively short time. As a result, it now has to deal with the negative impacts of tourism on several aspects of city life, and this is one of the most controversial current political issues. ${ }^{31}$ However, since the provision of local food and drinks is also an attraction factor for tourists, some areas may have increased tourism pressure because they already had higher alcohol availability. Outside the city, the evolution of this process in beach resorts has led to some areas becoming practically a tourist ghetto, avoided by many local residents, but this is not the current situation in the city. ${ }^{27}$ Further, while we expected socioeconomic level to strongly influence alcohol availability, ${ }^{9} 10$ it seems to play now a minor role. In the city of Madrid, which has not undergone such a rapid growth in tourism, socioeconomic level seems to be 
Table 2 Poisson regression models with robust error variance of the census tracts density of alcohol premises and alcohol promotion elements with neighbourhood tourism pressure and with socioeconomic level (AFII), Barcelona, 2017-2018

\begin{tabular}{|c|c|c|c|c|}
\hline & $\operatorname{IRR}_{\mathrm{c}}(95 \% \mathrm{Cl})$ & $P$ value & $\operatorname{IRR}_{\mathrm{A}}(95 \% \mathrm{Cl})$ & $P$ value \\
\hline \multicolumn{5}{|l|}{ Alcohol premises in general } \\
\hline Low tourism pressure & 1 & & 1 & \\
\hline Medium tourism pressure & $1.31(1.01-1.71)$ & 0.045 & $1.30(0.98-1.74)$ & 0.07 \\
\hline High tourism pressure & $2.52(1.90-3.35)$ & $<0.001$ & $2.50(1.85-3.38)$ & $<0.001$ \\
\hline Socioeconomic level (AFII) & $1.00(1.00-1.01)$ & 0.064 & $1.00(1.00-1.00)$ & 0.911 \\
\hline \multicolumn{5}{|l|}{ On-premises } \\
\hline Low tourism pressure & 1 & & 1 & \\
\hline Medium tourism pressure & $1.33(1.00-1.77)$ & 0.047 & $1.31(0.95-1.79)$ & 0.95 \\
\hline High tourism pressure & $2.78(2.06-3.77)$ & $<0.001$ & $2.72(1.96-3.76)$ & $<0.001$ \\
\hline Socioeconomic level (AFII) & $1.00(1.00-1.01)$ & 0.042 & $1.00(1.00-1.00)$ & 0.752 \\
\hline \multicolumn{5}{|l|}{ Off-premises } \\
\hline Low tourism pressure & 1 & & 1 & \\
\hline Medium tourism pressure & $1.27(0.91-1.77)$ & 0.161 & $1.31(0.92-1.86)$ & 0.133 \\
\hline High tourism pressure & $1.95(1.37-2.76)$ & $<0.001$ & $2.02(1.38-2.95)$ & $<0.001$ \\
\hline Socioeconomic level (AFII) & $1.00(1.00-1.00)$ & 0.368 & $1.00(1.00-1.00)$ & 0.669 \\
\hline \multicolumn{5}{|l|}{ Advertising and promotion } \\
\hline Low tourism pressure & 1 & & 1 & \\
\hline Medium tourism pressure & $1.20(0.89-1.62)$ & 0.237 & $1.18(0.86-1.64)$ & 0.308 \\
\hline High tourism pressure & $2.33(1.69-3.22)$ & $<0.001$ & $2.30(1.64-3.23)$ & $<0.001$ \\
\hline Socioeconomic level (AFII) & $1.00(1.00-1.01)$ & 0.088 & $1.00(1.00-1.00)$ & 0.841 \\
\hline \multicolumn{5}{|c|}{ Advertising and promotion in public places } \\
\hline Low tourism pressure & 1 & & 1 & \\
\hline Medium tourism pressure & $0.97(0.52-1.81)$ & 0.916 & $0.94(0.48-1.85)$ & 0.868 \\
\hline High tourism pressure & $1.18(0.60-2.33)$ & 0.623 & $1.15(0.55-2.43)$ & 0.707 \\
\hline Socioeconomic level (AFII) & $1.00(1.00-1.00)$ & 0.711 & $1.00(1.00-1.00)$ & 0.819 \\
\hline
\end{tabular}

Premises with alcohol advertising and promotion elements

\begin{tabular}{llrrrr}
\hline Low tourism pressure & 1 & \multicolumn{1}{c}{1} \\
\hline Medium tourism pressure & $1.21(0.90-1.63)$ & 0.202 & $1.19(0.86-1.64)$ & 0.229 \\
\hline High tourism pressure & $2.51(1.83-3.44)$ & $<0.001$ & $2.44(1.75-3.41)$ & $<0.001$ \\
\hline Socioeconomic level (AFII) & $1.00(1.00-1.00)$ & 0.064 & $1.00(1.00-1.00)$ & 0.735 \\
\hline
\end{tabular}

AFII, Available Family Income Index; IRR , adjusted incidence rate ratio; IRR , crude incidence rate ratio.

the leading factor explaining the distribution of alcohol elements, ${ }^{10}$ but this is not the case now in Barcelona. The current picture may reflect changes caused by expanding tourism pressure in the city in recent years, driven by the growth in tourist apartments displayed in Airbnb and similar platforms.

Overall, it seems that tourism is shaping cities in many ways. Probably its influence in gentrification and its impact on housing is a major effect, but also its impact in the local fabric of trade, including those aspects determining alcohol availability and promotion urban elements. The strong association found between tourism and these elements in the urban environments may contribute at least partially to the process of drinking normalisation and of trivialisation of the consequences of alcohol use both for residents and temporary visitors. ${ }^{32}{ }^{33}$ Of course, contextual factors related to alcohol culture and formal and informal regulations may be relevant and result in variations across countries. ${ }^{3} 4$ Traditional direct advertising seems to have evolved into a more subtle range of alcohol marketing elements. Most elements that promote alcohol in the city are not plain advertising, but rather items placed in alcohol premises with logos or brands (such as parasols, ashtrays or napkin holders). ${ }^{6}$ Repeated exposure to these elements is known to favour positive attitudes towards it (or greater preference for it), what is known as the 'mere exposure' effect. ${ }^{34}$ This is one of the mechanisms through which advertising and marketing 
techniques succeed, even when the target audience does not pay direct attention to the messages: simply perceiving a product or brand can affect behaviour and decisions. ${ }^{35}$ In fact, this advertising has been shown to increase drinking rates in target groups (mainly young people) in different countries. ${ }^{36-38}$ Therefore, a dense alcohol urban environment can induce more drinking by local residents, since a higher density of alcohol elements could act as advertising. ${ }^{39-41}$ Exploring whether this influence exists and its magnitude is a suggestive research to undertake in the process to disentangle the many factors influencing the harmful use of alcohol, which will require the contribution of different disciplines. Having documented urban alcohol environmental factors, we intend to analyse this relation further in future studies, using both qualitative and quantitative methods.

\section{CONCLUSIONS}

We observed a relationship between tourism pressure and density of alcohol outlets and alcohol advertising and promotion elements in Barcelona, which may influence alcohol use by the population. Future studies on the availability and marketing of alcohol as elements that may foster its use in urban areas should consider tourism pressure.

\section{Author affiliations}

${ }^{1}$ Agència de Salut Pública de Barcelona, Barcelona, Spain

${ }^{2}$ Institut d'Investigació Biomèdica Sant Pau, Barcelona, Spain

${ }^{3}$ Departament de Ciències Experimentals i de la Salut, Universitat Pompeu Fabra (UPF), Barcelona, Spain

${ }^{4}$ Centro de Investigación Biomédica en Red de Epidemiología y Salud Pública (CIBERESP), Madrid, Spain

${ }^{5}$ Public Health and Epidemiology Research Group. School of Medicine, University of Alcalá, Alcalá de Henares, Spain

${ }^{6}$ Department of Epidemiology \& Biostatistics, Graduate School of Public Health \& Health Policy, City University of New York, New York, United States

${ }^{7}$ Tobacco Control Research Group, Institut d'Investigació Biomèdica de BellvitgeIDIBELL, I'Hospitalet de Llobregat, Spain

${ }^{8}$ Consortium for Biomedical Research in Respiratory Diseases (CIBER en

Enfermedades Respiratorias, CIBERES), Madrid, Spain

${ }^{9}$ Faculty of Health Sciences, Universitat Oberta de Catalunya, Barcelona, Spain

${ }^{10}$ Departament de Psicobiologia i Metodologia en Ciències de la Salut, Universitat Autònoma de Barcelona (UAB), Bellaterra, Spain

${ }^{11}$ Facultat de Ciències de la Salut de Manresa, Universitat de Vic - Universitat

Central de Catalunya (UViCUCC), Manresa, Spain

${ }^{12}$ Department of Epidemiology, Johns Hopkins Bloomberg School of Public Health, Baltimore, United States

Contributors AE, JRV, XS and MF conceived the study. AE and SP supervised the fieldwork. AE and JRV designed and supervised the analytical procedures. SP prepared the database and analysed the data with the advice of JRV and AE. $S P, J R V$ and AE drafted the manuscript. SP, JRV, XS, MB-P, ET-C, MF, MB and AE contributed substantially to the interpretation of the data, reviewed and edited the manuscript, and approved its final version.

Funding This work was supported by Delegación del Gobierno para el Plan Nacional sobre Drogas (DGPNSD) grant numbers (20161047 and 2016l029) and by Spanish Network on Addictive Disorders grant numbers [RD12/0028/0018] and [RD16/0017/0013].

Map disclaimer The depiction of boundaries on this map does not imply the expression of any opinion whatsoever on the part of BMJ (or any member of its group) concerning the legal status of any country, territory, jurisdiction or area or of its authorities. This map is provided without any warranty of any kind, either express or implied.

Competing interests None declared.

Patient consent for publication Not required.

Provenance and peer review Not commissioned; externally peer reviewed.

Data availability statement Data are available upon reasonable request, such as collaborative research, at mbosquep@uoc.edu.

Open access This is an open access article distributed in accordance with the Creative Commons Attribution Non Commercial (CC BY-NC 4.0) license, which permits others to distribute, remix, adapt, build upon this work non-commercially, and license their derivative works on different terms, provided the original work is properly cited, appropriate credit is given, any changes made indicated, and the use is non-commercial. See: http://creativecommons.org/licenses/by-nc/4.0/.

ORCID iD

Marina Bosque-Prous http://orcid.org/0000-0002-8830-8880

\section{REFERENCES}

1 Alwan A, Armstrong T, Bettcher D, et al. Global status report: on noncommunicable diseases 2010. Lisbon, Portugal: World Health Organization, 2011.

2 GBD 2016 Alcohol Collaborators. Alcohol use and burden for 195 countries and territories, 1990-2016: a systematic analysis for the global burden of disease study 2016. Lancet 2018;392:1015-35.

3 Babor TF, Caetano R, Casswell S, et al. Alcohol: no ordinary commodity: research and public policy. New York: Oxford University Press, 2010.

4 Bosque-Prous M, Espelt A, Guitart AM, et al. Association between stricter alcohol advertising regulations and lower hazardous drinking across European countries. Addiction 2014;109:1634-43.

5 Bosque-Prous M, Espelt A, Borrell C, et al. Gender differences in hazardous drinking among middle-aged in Europe: the role of social context and women's empowerment. Eur J Public Health 2015;25:698-705.

6 Sureda X, Carreño V, Espelt A, et al. Alcohol in the city: wherever and whenever. Gac Sanit 2018;32:172-5.

7 Mori-Gamarra F, Moure-Rodríguez L, Sureda X, et al. [Alcohol outlet density and alcohol consumption in Galician youth]. Gac Sanit 2020;34:15-20.

8 Murphy A, Roberts B, Kenward MG, et al. Using multi-level data to estimate the effect of social capital on hazardous alcohol consumption in the former Soviet Union. Eur J Public Health 2014;24:572-7.

9 Hay GC, Whigham PA, Kypri K, et al. Neighbourhood deprivation and access to alcohol outlets: a national study. Health Place 2009;15:1086-93.

10 Pastor A, Espelt A, Villalbí JR, et al. Availability and promotion of alcohol across different outlet typologies and under different arealevel socioeconomic status. Adicciones 2020:1367.

11 Schneider S, Gruber J. Neighbourhood deprivation and outlet density for tobacco, alcohol and fast food: first hints of obesogenic and addictive environments in Germany. Public Health Nutr 2013;16:1168-77.

12 Angus C, Holmes J, Maheswaran R, et al. Mapping patterns and trends in the spatial availability of alcohol using low-level geographic data: a case study in England 2003-2013. Int J Environ Res Public Health 2017; 14:406.

13 Livingston M. The social gradient of alcohol availability in Victoria, Australia. Aust N Z J Public Health 2012;36:41-7.

14 Örnberg JC, Room R. Impacts of tourism on drinking and alcohol policy in low-and middle-income countries: a selective thematic review. Contemp Drug Probl 2014;41:145-69.

15 Villalbí JR, Espelt A, Sureda X, et al. The urban environment of alcohol: a study on the availability, promotion and visibility of its use in the neighborhoods of Barcelona. Adicciones 2019;31:33-40.

16 Maranda MJ. Drug and alcohol consumption in Cyprus. The Cyprus Review 1996;8:111-8.

17 Barcelona PFL. De ciutat Amb turisme a ciutat turística. notes sobre un procés complex I inacabat. Documents d'an lisi geogr fica 2015;61:483-506.

18 Observatori del Turisme a Barcelona. Barcelona tourism activity report. Barcelona: Ajuntament de Barcelona, 2017.

19 Barcelona Turisme. Tourism statistics: Barcelona City and region. Barcelona, 2016. 
20 Jiménez S, Prats L. El turismo en Cataluña: evolución histórica $Y$ retos de futuro. Pasos Revista de turismo y patrimonio cultural 2006;4:153-74.

21 Bell D. Destination drinking: toward a research agenda on alcotourism. Drugs 2008;15:291-304.

22 Stone MJ, Soulard J, Migacz S, et al. Elements of memorable food, drink, and culinary tourism experiences. J Travel Res 2018;57:1121-32.

23 Lambea Llop N. A policy approach to the impact of tourist dwellings in condominiums and neighbourhoods in Barcelona. Urban Res Pract 2017;10:120-9.

24 Grant M. Alcohol policies. Copenhagen:New York: WHO Regional Office for Europe, 1985.

25 Sureda X, Espelt A, Villalbí JR, et al. Development and evaluation of the OHCITIES instrument: assessing alcohol urban environments in the heart healthy hoods project. BMJ Open 2017;7:e017362.

26 Briassoulis H, Straaten JVD, Briassoulis H. Tourism and the environment: regional, economic, cultural and policy issues. London: Springer, 2010.

27 Barcelona Regional. Pla especial urbanístic per a l'ordenació dels establiments d'allotjament turístic, albergs de joventut, residències col-lectives d'allotjament temporal $i$ habitatges d'ús turístic a la ciutat de Barcelona. Barcelona: Ajuntament de Barcelona, 2016.

28 Barcelona Economia. Distribució territorial de la Renda familiar Disponible per C pita a Barcelona (2016. Barcelona: Ajuntament de Barcelona, 2017.

29 Gruenewald PJ, Ponicki WR, Holder HD. The relationship of outlet densities to alcohol consumption: a time series cross-sectional analysis. Alcohol Clin Exp Res 1993;17:38-47.
30 Pearce J, Day P, Witten K. Neighbourhood provision of food and alcohol retailing and social deprivation in urban New Zealand. Urban Policy and Research 2008;26:213-27.

31 Mason P. Tourism impacts, planning and management. Second ed. Amsterdam: Taylor \& Francis, 2008.

32 Moore RS. Gender and alcohol use in a Greek tourist town. Ann Tour Res 1995;22:300-13.

33 Sureda X, Villalbí JR, Espelt A, et al. Living under the influence: normalisation of alcohol consumption in our cities. Gac Sanit 2017;31:66-8.

34 Zajonc RB. Attitudinal effects of mere exposure. J Pers Soc Psychol 1968;9:1-27.

35 Ruggieri S, Boca S. At the roots of product placement: the mere exposure effect. Europe's Journal of Psychology 2013;9:246-58.

36 Barve G, Sood A, Nithya S, et al. Effects of advertising on youth (age group of 13-19 years age). J Mass Commun 2015;5:1-9.

37 Hanewinkel R, Sargent JD, Poelen EAP, et al. Alcohol consumption in movies and adolescent binge drinking in 6 European countries. Pediatrics 2012;129:709-20.

38 Committee on Communications, American Academy of Pediatrics, Strasburger VC. Children, adolescents, and advertising. Pediatrics 2006;118:2563-9.

39 Patil S, Winpenny EM, Elliott MN, et al. Youth exposure to alcohol advertising on television in the UK, the Netherlands and Germany. Eur J Public Health 2014;24:561-5.

40 Petticrew M, Shemilt I, Lorenc T, et al. Alcohol advertising and public health: systems perspectives versus narrow perspectives. $J$ Epidemiol Community Health 2017;71:308-12.

41 Ross CS, Henehan ER, Jernigan DH. Youth exposure to alcohol advertising in national magazines in the United States, 2001-2011. Am J Public Health 2017;107:136-42. 